\title{
LAS COMUNIDADES LIBANESAS Y SU INCIDENCIA EN LA PROBLEMATICA ACTUAL
}

\author{
Clara $M^{a}$ Thomas de Antonio
}

Para entender la actual situación del Líbano es necesario conocer la gran variedad de comunidades ( $t \hat{a}^{\circ} i f a$, pl. taw $\left.\hat{a}^{\supset} i f\right)$ que lo habitan, ya que en ellas se basa su sistema político,

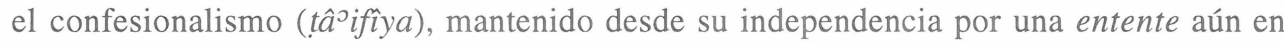
vigor ${ }^{1}$.

El origen de la población del Líbano es muy variado por la multitud de pueblos que han pasado por sus tierras y que han dejado su huella. La etnia dominante es la árabe, aunque no hay que desdeñar la primitiva aramea, la kurda, la armenia, la judía o la franca. La lengua principal es el árabe, aunque existe un 5\% que habla el armenio, y otras lenguas persisten en el culto de algunas sectas. También se hablan el francés (sobre todo en ciertas familias cristianas), el inglés (que va reemplazándolo), e incluso el español.

Sin embargo, la división racial tiene escasa importancia frente a la religiosa, pues estas comunidades y sus organizaciones dominan la vida del país. La maronita y la drusa tienen su centro histórico en el Líbano; las demás, aunque asentadas desde antiguo (excepto la armenia, de reciente implantación), son ramas de comunidades más amplias extendidas por todo el mundo oriental.

\section{CRISTIANOS ${ }^{2}$}

Están divididos en tres ramas básicas: los católicos (fieles a Roma) y los ortodoxos y protestantes (separados de ella). A su vez, éstas se subdividen en un amplio número de comunidades. Algunas de ellas tienen su origen en la política autoritaria de Bizancio en el s. $\mathrm{V}$, que dio lugar al nacimiento de varias herejías cuya disidencia giraba en torno a la interpretación del misterio de la encarnación de Cristo: la nestoriana (que reconocía en Cristo dos naturalezas separadas, la divina y la humana) de la que deriva la Iglesia nestoriana; la monofisita (que casi negaba la naturaleza humana de Cristo, perdida en la divinidad) de la que derivan los jacobitas o siro-ortodoxos y los coptos de Egipto; y la

\footnotetext{
1 Para evitar largas notas se ha elegido el sistema "autor-fecha-página" referido a la bibliografía final. En cuanto a los nombres propios y topónimos se ha optado por la grafía más conocida para el lector medio, siendo acompañada -en su primera aparición y entre paréntesis- por la trascripción del término árabe.

2 Alem, 1968, 13-14; Longrigg, 1958, 10-12; Gordon, 1980, 143; Tibawi, 1969, 439; Hopwood, 1988, $11,16$.
} 
monotelita (que, respetando el dogma de la unión hipostática de las dos naturalezas de Cristo, afirmaba que en Él sólo existía una voluntad, la divina) cuya importancia radica en que, al parecer, fue adoptada durante un tiempo por los maronitas.

Los cristianos se diferencian poco -con excepción de los armenios- del resto de la población musulmana, pues han asimilado en buena parte su modo de vida, su lengua y su cultura. Ha habido siglos de coexistencia familiar en el mismo territorio y han compartido los orígenes raciales y el legado cultural árabe. Sin embargo, el maronita se siente maronita, el ortodoxo se siente griego, mientras que a los ojos de los cristianos el musulmán es un turco ${ }^{3}$.

Salvo los maronitas, cuya mayoría es rural, el resto de los cristianos muestran preferencia por la vida ciudadana. Son grupos muy relacionados entre sí por su común status y distinción frente al Islam; pero a su vez están netamente divididos por su autonomía interna celosamente preservada, su exclusivismo social, sus diferencias de doctrina, de centros de culto y educación, y su variada actitud política. Por otro lado, los cristianos eran tratados por los musulmanes con liberalidad, como "Gentes del Libro", y en tiempos otomanos sus millets eran autónomos. Sus prelados eran muy influyentes dentro y fuera de la comunidad. Por lo común, los cristianos gozaban de buena posición en la esfera económica y cultural y se les podía considerar favorecidos frente a otras minorías. Además mantenían desde antiguo buenas relaciones con Occidente, debido en parte a la orientación de sus íglesias: ya en el s. XIX se beneficiaron de la labor de los misioneros (que les ofrecían escuelas de educación occidental y hospitales) y de los cónsules extranjeros (que les brindaban su protección frente a la posible hostilidad musulmana). Todo esto les hizo más receptivos a lo occidental y, aunque no tuvieron el monopolio de la occidentalización, serán más abiertos en general que los musulmanes.

\section{CATOLICOS.}

Los árabes católicos ( $k \hat{a} \underline{t} \hat{u} l \hat{l} k \hat{\imath}$, pl. kât Occidente, especialmente con Francia. De ahí que fueran reacios al nacionalismo árabe y acusados de preferir a Occidente frente al mundo árabe. Son más numerosos en Líbano que en Siria y han gozado de los beneficios proporcionados por los misioneros católicos (Jesuitas, Lazaristas, Hermanas de la Caridad, monjas de S. José) ${ }^{4}$. Están divididos en buen número de comunidades: maronitas, greco-católicos, armenio-católicos, siro-católicos, caldeos y latinos.

\footnotetext{
3 Según un diccionario de viaje de 1908, citado por Gordon (1980, 143).

4 Tibawi, 1969, 105; Hopwood, 1988, 11-12.
} 
- Maronitas 5 .

Los orígenes de los maronitas (mârûnî, pl. mawârina) y su trayectoria histórica hạ sido muy discutidos. Varios autores libaneses posteriores al s. XVII los identifican con los mardaítas; pero esta tesis es insostenible, ya que éstos estaban implantados en el Líbano cuatro siglos antes que los maronitas. El mito de identidad con los mardaítas hallaría expresión en 1976, cuando una milicia maronita se apodó Brigada Mardaíta (Liwâa alMarada).

Según Benassar (1978, 212), su iglesia surge en el año 451 del Concilio de Calcedonia, en una época de crisis en que las Iglesias de Oriente se separan del Papado. Pero los maronitas permanecieron fieles a Roma, consolidando su fe en tiempos' de las cruzadas. Implantados en Homṣ (Siria), en el s. VI se desplazan a la montaña libanesa por los cambios políticos y de rito de Bizancio. Desde allí se expanden por todo el Líbano y, a partir de 1860, por todo el mundo. Compartieron las montañas -Becharre (Bisarrî), Kesruan (Kisrawân), Metn (Matn)- con las sectas Šî́íes, para acabar controlando la zona. A finales del XVIII emigran al Chuf (Ŝ̂f), donde está la mitad de la comunidad, a Jezzine (Ŷazîn) y Beirut (Bayrût).

Alem $(1968,20-21)$ expone otra tesis sobre sus orígenes. Cuando el piadoso Mârûn muere en el año 423, sus fieles construyen el convento de Mâr Mârûn para depositar sus restos. El convento desarrolla gran actividad y extiende su influencia por la región. Al propagarse la herejía monotelita, parece que sus monjes se unen a ella y se convierten en sus más fervientes defensores. Uno de esos monjes, Yûhannâ Mârûn, crea la Iglesia Maronita en el año 685, y se convierte en Patriarca de Antioquía -donde ya existían el melkita y el jacobita-, llevando desde entonces el título de "Patriarca de Antioquía y de todo Oriente". Pronto sufren las persecuciones de los bizantinos y dificultades con los jacobitas. En el año 685 su principal monasterio cerca de Antioquía es destruido y tienen que abandonar la zona y refugiarse en Rastan, entre Homș y Ḥamâh. Pero la invasión árabe les hace emigrar de nuevo para preservar su autonomía. Bordeando la costa, suben al Valle Santo o Valle de la Qadîsa, donde se atrincheran, y desde el s. VIII la montaña libaniesa será su hábitat. Se extienden luego a Kesruan y Jbail (Ŷubayl) y a los feudos drusos del Metn y el Chuf. A partir de ese núcleo, y tras mezclarse con los autóctonos greco-fenicios de la costa, los arameos del interior, los mardaítas, los francos y los armenios de los momentos de las cruzadas, constituyen la actual comunidad, localizada en el Monte Líbano, la Bekaa $\left(B i q \hat{a}^{c}\right)$ y las ciudades costeras. Los maronitas volvieron a la obediencia romana en 1182, al alinearse en las cruzadas, pero es tan fuerte su comunión con Roma que han negado haberse separado de ella, a pesar de lo que dicen la mayoría de las fuentes no-maronitas.

La iglesia maronita ejerce gran autoridad. Su liturgia se celebra en siriaco y también en árabe. Su patriarca es elegido de por vida por el Sínodo de metropolitanos y obispos, y su elección es confirmada por Roma con el envío de un palium; en invierno reside en Bkerké

\footnotetext{
5 Alem, 1968, 20-21, 107, 113-114; Gordon, 1980, 37-38; Longrigg, 1958, 13-14; de Bar, 1983, 106, 109-113, 115-116; Palazzoli, 1977, 59; Benassar, 1978, 212-213; Hopwood, 1988, 11.
} 
(Bkirkî), cerca de Beirut, y en verano en Dîmân, en el Valle Santo; tiene jurisdicción sobre todos los maronitas del ex-Imperio Otomano. En el Líbano hay seis obispados: Tiro (Șûr)Haifa; Sidón (Șaydâ); Beirut; Antelías-Chipre; Sarbâ-Jounieh (Ŷ̂uniyah); y Trípoli (Tarâbulus).

De carácter viril y fuerte sentimiento comunitario, el recuerdo de sus luchas en los valles y de su imperio local y el dominio de su poderoso clero les dio un cierto carácter de nación en miniatura. Bajo los otomanos gozaron de un estatuto autónomo, algo sin paralelo en dicho Imperio. Posteriormente Francia crearía el actual estado del Líbano en torno a ellos. En 1861 eran el 76\% de la población del monte Líbano. Según el censo de 1932, eran la mayor secta del Gran Líbano (28,53\% de la población). En 1975, eran la comunidad más poderosa, con 600.000 ó 700.000 miembros, y controlaban los puestos claves del gobierno y la administración. Hoy día, sin haber superado las cifras de 1975, constituyen entre el $28 \%$ y el $25 \%$ de la población.

Ocupan un lugar preeminente en el país por su número, cultura y actividad. En la montaña son agricultores, de acuerdo con su primitivo origen, pero actualmente también están bien implantados en la industria turística debido al atractivo de la zona. En las ciudades, son minoría: en principio comerciantes, funcionarios o de profesiones liberales, han ido tomando posiciones en la banca, el sector inmobiliario, la hostelería y la industria. En Beirut forman la mayor parte de la burguesía, como cuadros de la administración y profesionales liberales, aunque en este monopolio van sufriendo la competencia de los armenios y greco-ortodoxos, así como la más reciente de los sunníes y šîcíes. Cuentan con su propia prensa y su posición es relativamente acomodada: parte de su poder se cifra en la gran riqueza de su iglesia, en los medios que le proporciona su abundante emigración y en sus relaciones privilegiadas con Occidente.

Al ser la $1^{\text {a }}$ comunidad del país, dominan las más altas magistraturas y los mejores puestos en la administración, los empleos públicos y el ejército. Desde 1943 ocupan la Presidencia de la República: Bišâra al-Jûrî (1943-1952), Camille Chamún (Šamª̂n) (19521958), Fưâd Chehab (Šihâb) (1958-1964), Charles Helou (1964-1970), Sulaymân Frangié (1970-1976), Elías Šarkîs (1976-1982), Bašîr Gemayel (Ŷumayyil) (1982), Amîn Gemayel (1982-1988) y Elías Hiarâwî (desde 1989).

- Están muy fragmentados en clanes, basados en un fuerte individualismo y en el prestigio personal de sus líderes. También cuentan con 4 formaciones políticas: el Destur (al-Dustûr), de Jalîl al-Jûrî, partidario de ceder en sus privilegios en función de la unidad nacional; las Falanges $\left(K_{a t} \hat{a}^{i} i\right)$, de Pierre Gemayel, formación de masas enemiga del panarabismo sunní; el Bloque Nacional (Al-Kutla al-Watanîya), de Raymond Eddé, partido de cuadros cercano al de Yumblat, antichehabista y partidario de la independencia libanesa y el liberalismo; el Partido Nacional Liberal (Hizb al-Wațnîyîn al-Ahrâr), de Camille Chamún, que comparte con las Falanges y el Bloque su resistencia al naserismo sunní. Aliados con otras confesiones, los maronitas cuentan con 32 escaños en la Cámara. A pesar de su fraccionamiento, se unen a su iglesia cuando la independencia del Líbano se ve amenazada. Deseando escapar al predominio musulmán, son reacios al nacionalismo árabe y luchan 
contra los sunníes por conservar el Líbano cristiano. Sacan ventaja del sistema confesional e intentan mantener sus privilegios, a pesar de tener actualmente más representación de la que les correspondería. Son una comunidad en declive relativo, amenazada por el crecimiento musulmán.

- Greco-católicos ${ }^{6}$.

Los greco-católicos (rûm kâtûtîk) proceden de una escisión de los greco-ortodoxos de Constantinopla. Se unieron a Roma en 1727, aceptando las decisiones del Concilio de Calcedonia (año 451). También son llamados melkitas -hombres del rey (malik)- por haber permanecido fieles al emperador. En la actualidad se reserva el nombre para estos católicos de liturgia bizantina, en griego y en árabe. Su "Patriarca de Antioquía, Alejandría, Jerusalem y el resto de Oriente", que ha cambiado mucho de lugar de residencia, vive en cAyn Tirâz, cerca de ${ }^{\mathrm{c}}$ Alîh. Hoy día se les encuentra en los pueblos del Chuf, en Zahla (su centro, con 30.000 almas), en las aldeas de la Bekaa y en Beirut.

Son unos 200.000 ó 230.000 y forman una comunidad de clases cultas, ciudadanas o rurales. Se les puede equiparar con los greco-ortodoxos por su educación occidental y la distinción de sus adeptos, aunque son más ricos que ellos. Juegan un buen papel en la economía y se les halla en el mundo de las altas finanzas, la industria y el comercio.

Políticamente tienen una importancia relativa. Eran la $6^{\text {a }}$ comunidad en 1932 y les está reservado uno de los 6 ministerios clave. En el arco parlamentario se sitúan a la derecha, por ser partidarios del liberalismo económico y representantes de los intereses de los católicos, los empresarios, la propiedad territorial, las profesiones liberales y la alta administración. Aliados de los maronitas -especialmente de Chamún- junto a otras comunidades, como la šîcí, son libanesistas en política, pero culturalmente arabistas.

- Armenio-católicos ${ }^{7}$.

Los armenios (armanî, pl. arman) católicos son una minoría desgajada del tronco gregoriano-ortodoxo en el s. XVIII. Su líder, "Patriarca de Constantinopla", reside en Beirut. El grueso de ellos está en Alepo (Siria), pero en el Líbano ocupan un irrelevante $10^{\circ}$ lugar.

- Siro-católicos ${ }^{8}$.

Los siro-católicos son una comunidad formada por siro-ortodoxos (jacobitas) convertidos al catolicismo. Conservan su liturgia en siriaco. Su "Patriarca de Antioquía" residió en Mârdîn (Turquía) o en Antioquía, pero ahora reside en Beirut y en verano en Ḥarîșâ (Kisrawân). Son escasos en Siria y aún más en Líbano, donde ocupan el puesto $12^{\circ}$, por lo que su papel es insignificante.

\footnotetext{
${ }^{6}$ Gordon, 1980, 38; Alem, 1968, 108-109; Palazzoli, 1977, 58-59; Rondot, 1978, 72; Longrigg, 1958, 13; de Bar, 1983, 59, 70-73.

7 Alem, 1968, 109; Gordon, 1980, 38; Longrigg, 1958, 13.

${ }^{8}$ Longrigg, 1958, 12; Palazzoli, 1977, 59; Alem, 1968, 108; Gordon, 1980, 38.
} 
- Caldeo-católicos ${ }^{9}$.

Los caldeos (kaldânîyûn) católicos son ex-nestorianos que se unen a Roma en el s. XIII. Forman parte de la Iglesia de Mesopotamia, esencialmente iraquí. Su "Patriarca de Babilonia" reside en Mosul o en Bagdag. Usan el siriaco en su liturgia. Son muy poco numerosos -ocupan el $14^{\circ}$ lugar- y viven sobre todo en las ciudades.

- Latinos $^{10}$.

Los latinos (lâtînîyûn) son católicos de rito latino, con escasísima presencia en el Líbano. Dependen de la diócesis de Beirut, cuyo titular en los años 60 era americano.

\section{ORTODOXOS.}

La Iglesia Ortodoxa Oriental es la iglesia más antigua independiente de Roma y ha seguido un proceso de fragmentación similar al de la iglesia armenia. Los seguidores del rito ortodoxo representan el 75\% de los cristianos en el conjunto de la zona siro-libanesa. En el Líbano son más escasos que en Siria ${ }^{11}$. Están divididos en varias comunidades: grecoortodoxos, armenio-gregorianos, siro-jacobitas y nestorianos.

- Greco-ortodoxos ${ }^{12}$.

La mayoría de los ortodoxos libaneses pertenecen a esta comunidad. Los greco-ortodoxos (rûm urțûduks) son los descendientes de los habitantes del Líbano de época Bizantina, y por ello los libaneses más antiguos. Arameos más puros que los maronitas, son por su comportamiento los cristianos más árabes del Líbano. Los omeyas no persiguieron a estos cristianos ya implantados en el país, sino que les incorporaron a la corte y a la administración, respetando sus creencias. De ahí deriva quizás su buen entendimiento con los sunníes. Dependen de una iglesia exterior, la Iglesia de Antioquía o la Iglesia Ortodoxa de Rusia y Grecia, y fueron gobernados por un patriarca griego residente en Constantinopla. Como su jerarquía -también griega y ausente- descuidaba su iglesia local, los fieles y el clero se resintieron amargamente y a fines del XIX lograron elegir a un patriarca árabe en Damasco, elección descrita como "la primera victoria real del nacionalismo árabe". Este hecho es indicativo de la devoción de los árabes ortodoxos por la causa del nacionalismo. Para salvar el espinoso problema de ser verdaderamente árabes sin ser musulmanes, tuvieron que poner más énfasis en lo que les unía (raza, lengua, nacionalidad, herencia cultural) que en lo que les separaba, aunque manteniendo su propia identidad. En 1914 retenían poco de su origen griego en su liturgia y en su clero. Su patriarca árabe, que lleva también el título de "Patriarca de Antioquía y de todo Oriente", reside en Damasco y mantiene excelentes

\footnotetext{
9 Longrigg, 1958, 12; Gordon, 1980, 39; Alem, 1968, 108; Palazzoli, 1977, 59.

10 Longrigg, 1958, 12; Alem, 1968, 109.

11 Rondot, 1978, 72: Longrigg, 1958, 13.

12 Alem, 1968, 16, 107-109; Longrigg, 1958, 13; Hopwood, 1988, 10-11; F.M.A., I-L17; Gordon, 1980, 39; Koury, 1976, 2; De Bar, 1983, 39, 41, 46-47, 51, 53-54.
} 
relaciones con Moscú. Esta iglesia árabe, muy protegida por Rusia -ya que así se aseguraba una posición en Tierra Santa-, pierde esa protección en 1917, cuando los comunistas llegan al poder. Por ello quizás decide unir su suerte a la de la mayoría musulmana.

La comunidad, con 265.000 miembros estimados en 1976, está diseminada por el Líbano central y Beirut, donde tiene una fuerte representación, aunque su epicentro está en la montaña. Cuentan con hombres y familias de alto nivel e instituciones bien organizadas. Suelen ser ciudadanos y prósperos hombres de negocios, formando una burguesía mercantil o de profesiónes liberales. Más instruidos que el conjunto de los musulmanes, tienden a oficios de cuello blanco; pero muchos de sus apellidos atestiguan un pasado artesanal: Ḥaddâd (herrero), Șầig (orfebre), Laḥhâm (carnicero).

Políticamente, ocupan el $4^{\circ}$ lugar entre las comunidades libanesas, por lo que les está reservado el puesto de Vice-Presidente de la Cámara y uno de los seis ministerios clave, el de Asuntos Exteriores. Sin embargo, al crearse el Líbano, el primer Presidente de la República fue el greco-ortodoxo Charles Debbas. En general están satisfechos con el reparto de escaños y, a pesar de sus inquietudes revolucionarias, refuerzan en la Cámara a los conservadores.

Debido a su historia se consideran parte del mundo árabe. Son partidarios de la Gran Siria y también hay entre ellos grandes teorizadores del panarabismo, como Qusțantîn Zurayq, Mîjầ̂îl cAflaq, Antûn Sacâda o George Habbache. Son a la vez un activo fermento revolucionario, pues luchan contra cualquier forma de imperialismo occidental anti-árabe, como puedan ser el capitalismo o el sionismo. Se oponen a las comunidades católicas, especialmente a los maronitas, por considerarlas vueltas a Occidente y antiárabes. En los choques de 1841 los greco-ortodoxos se unen a los drusos contra los maronitas, y en 1842, prefieren vivir en la zona drusa. A pesar de ello, suelen aliarse con los sunníes en la defensa del panarabismo o el pansirianismo.

\section{-Armenio-ortodoxos o gregorianos ${ }^{13}$.}

La iglesia armenia ortodoxa -de la que luego se segregaría un reducido grupo de católicos y protestantes- se separa de Roma el año 491. La mayor parte de los armenios gregorianos ( grîgûrî) reconocen la autoridad de la iglesia autocéfala gregoriana, una amplia organización internacional con patriarcas regionales. A su cabeza están, paradójicamente, dos católicos, y los armenios gregorianos del Líbano dependen del catolicosado de Antelías. Originarios de Anatolia y de raza indoeuropea, emigraron al Líbano en época reciente: en 1914, apenas eran unos dos o tres mil; huyendo de las aterradoras persecuciones de los turcos llegarían en dos oleadas sucesivas: en 1918, al evacuar los franceses la Cilicia, y en 1939, cuando éstos ceden Alejandreta a los turcos.

Al principio, aun siendo tratados con la misma liberalidad que los demás cristianos, vivieron en miserables condiciones; pero, gracias a su coraje e inteligencia, lograron ocupar un destacado lugar en Beirut, donde su comunidad cuenta con cerca de 100.000 miembros.

${ }^{13}$ Alem, 1968, 15n1, 108; Longrigg, 1958, 13; de Bar, 1983, 75-76, 86, 94-95. 
Hoy día se han integrado y hablan el árabe, aunque muchos conservan el armenio. Cuentan con una clase cultivada, y a menudo rica, de negociantes e industriales, pero la mayoría son modestos comerciantes y artesanos. Forman parte de la clase media libanesa y son en su mayoría ciudadanos.

Respetuosos con las instituciones del país, formaban la $7^{\mathrm{a}}$ comunidad por su número en 1932, pero su papel no es muy relevante, a excepción de una pequeña y activa minoría comunista. Sus aspiraciones están más dirigidas hacia el país armenio, por lo que han conservado fuertes organizaciones comunitarias ligadas a sus partidos: Tachnak, el más activo y poderoso, y a su izquierda el Ramkavar y el Hintchak. Aún estando al margen de la política, tienden al libanesismo, pero están descontentos con su asignación de escaños.

- Siro-ortodoxos o jacobitas ${ }^{14}$.

Los siro-ortodoxos o jacobitas (yac qûbî, pl. yachqiba), adeptos a la herejía monofisita, surgen en el año 543, cuando el monje Jacques Baradai -de donde procede su nombre- funda su iglesia. Su patriarca está en Mârdîn, su lengua litúrgica es el siriaco, y se proclaman descendientes de los antiguos arameos de la región. Son una pocas miles de almas, repartidas entre Beirut y la Bekaa, ocupando el puesto $n^{\circ} 13$. Con su doctrina y su organización diferentes, se mezclan fácilmente con sus vecinos y tienen distinguidos portavoces.

- Nestorianos ${ }^{15}$.

El origen de los nestorianos (nustûr, pl. nasâtir) data de la herejía de Nestorio (s. V). Su iglesia, con unas 200 diócesis, se diseminaría después hasta los confines extremos de Asia. Pero hoy día son poco numerosos, a excepción de los 350.000 de la costa Malabar. Son supervivientes de la raza asirio-caldea y vinieron al Líbano huyendo de las masacres de 1933 en Iraq. Hoy día son una comunidad de unos pocos cientos de miembros, en general aldeanos.

\section{PROTESTANTES ${ }^{16}$.}

Los protestantes (brûtustântîyûn) son muy escasos en el país. Sus pequeñas comunidades, anglicanas o presbiterianas, están formadas por antiguos ortodoxos convertidos por las misiones británicas o americanas. Su mayor importancia radica en haber fundado la Universidad Americana de Beirut y en la distinción personal de algunos de sus conversos. En general han rivalizado con los católicos, especialmente en el terreno cultural. También existe una exigua minoría armenia protestante.

\footnotetext{
14 Alem, 1968, 14: Longrigg, 1958, 12; Palazzoli, 1977, 58.

15 Gordon, 1980, 39; Alem, 1968, 13-14; Palazzoli, 1977, 59.

16 Palazzoli, 1977, 59; Longrigg, 1958, 12; Tibawi, 1969, 88-89.
} 
JUDIOS $^{17}$.

Más numerosos en épocas pasadas, el número de judíos (yahûdî, pl. yahûd) se ha ido reduciendo con el paso del tiempo. En 1932 eran la $8^{\text {a }}$ comunidad en el Líbano, pero muchos de ellos se han ido marchando a Israel. Aún así, en 1975 mantenían una sinagoga y una escuela en el centro de Beirut. Hoy día son más numerosos, debido a la ocupación israelí del Sur del Líbano. En general han sido bien tratados por los musulmanes, como "Gentes del Libro", y en tiempos de tensión, al menos antes de la guerra civil, tenían una protección especial, por evidentes razones simbólicas, por parte del ejército, las Falanges y la OLP.

\section{YAZIDIES 18}

Los yazîdíes libaneses no son más que un puñado de adeptos de una secta sincretista llamada de "adoradores del diablo". Consideran que Satán -visto en forma de pavo real sagrado- es un ángel caído que un día volverá a Dios. Su liturgia es árabe, aunque hablan el dialecto kurdo.

\section{MUSULMANES.}

Son en su mayoría de raza árabe, y su historia está ligada a la expansión del Islam y a su Imperio, en el que han sido predominantes. En el Líbano eran una ajustada minoría respecto a los cristianos en la época del Mandato, pero han crecido, siendo hoy mayoritarios. Debido a los avatares históricos de todos conocidos, se dividieron en varias ramas: una ortodoxa (sunnî) y varias heterodoxas o disidentes ( $\left.\breve{s}_{\imath} c i e s\right)$, frecuentemente enfrentadas con el Islam oficial. Aunque los musulmanes no tienen clero, sus magistrados religiosos (qâdíes) tienen gran relevancia social. A la cabeza de sus comunidades está un Muftî.

\section{SUNNIES ${ }^{19}$}

Son los representantes de la ortodoxia islámica. El sunnismo -derivado de sunna (tradición del Profeta)- procede de la rama que logra acaparar el califato. El Imperio Otomano pretendió ser su continuador, y de ahí su predominio en la mayor parte de los países árabes. Divididos en varias escuelas jurídicas, en el Líbano predomina la Hanafí. Su Gran Muftî, residente en Beirut, se declara jefe religioso de todos los musulmanes, incluidos los disidentes $\breve{s}^{1}{ }^{c} i ́ e s$, aunque en el Mandato se reconoció la existencia separada de éstos últimos, para evitar que se unieran contra Francia.

\footnotetext{
17 Gordon, 1980, 39.

18 Gordon, 1980, 39-40.

19 Benassar, 1978, 213; de Bar, 1983, 25-29, 34-37; F.M.A., I-L17; Alem, 1968, 109, 114; Longrigg, 1958, 7; Gordon, 1980, 40.
} 
Los sunníes (479.499 en las estimaciones de 1976) están repartidos por las costas, donde dominan los puertos desde hace tiempo: son dueños de Beirut, Trípoli y Sidón. También puede hallárseles en el monte ${ }^{c}$ Akkâr, el Chuf, Arkûb, Akrûm y la Bekaa, con una implantación muy fragmentada y puntual, sin vías de comunicación entre sus asentamientos.

En sus manos está el 15\% de la riqueza del país, especialmente por los bienes habices (waqf) de su comunidad, conseguidos a costa de los šścíes. Socialmente, se yuxtapone el mundo de los desheredados al de sus 200 familias ricas: frente a las grandes familias urbanas (de capital improductivo, o con intereses en la industria de transformación, importación y exportación en los puertos) o terratenientes en el campo, y una pequeña burguesía (de profesionales liberales, funcionarios, empleados y comerciantes) están las masas sunníes, subempleadas y pobres, a menudo atraídas por los partidos progresistas y socializantes.

Desde siempre han sido tolerantes con los greco-ortodoxos, llegando incluso a una cierta simbiosis con ellos, pues son vecinos en muchos enclaves y su apariencia y valores se asemejan. Intelectualmente son menos abiertos que los cristianos, están menos penetrados por la influencia occidental, aunque no han escapado a ella, y suelen tener una formación de tipo tradicional. Económica y culturalmente son una comunidad relativamente más próspera,

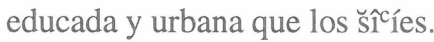

Los sunníes libaneses viven, nacen y mueren con el sentimiento de ser árabes. Forman el elemento dominante -la calle- de las principales ciudades del litoral. Por ello dirigen la vida ciudadana y tienen gran importancia política, como se demostraría en los incidentes de 1958. La división de Beirut en dos zonas, durante la guerra de 1975-76, modifica esa intangible realidad de preeminencia política en la capital.

Por su número formaban en 1932 la $2^{\text {a }}$ comunidad del país, aunque hoy día están siendo sobrepasados por los šî́íes. Por ello se les asigna desde 1943 la Presidencia del Gabinete o puesto de Primer Ministro, destacando los incombustibles Rašîd Șulh y Rašîd Karamé (Karâmî).

Aunque desunidos y contradictorios, cuentan con sus propias milicias, las Naŷŷấes, varias veces prohibidas, que defienden las tesis extremas del arabismo. Como miembros de la Umma, su sueño es ser dominantes en el Fértil Creciente o en una unión más amplia de países árabes; de ahí su defensa del pansirianismo y el panarabismo, junto con los grecoortodoxos. Sin embargo, han participado en la entente de 1943 y han mantenido el statu quo.

\section{$\mathrm{SI}^{\mathrm{C}} \mathrm{ISMO}^{20}$.}

Los heterodoxos islámicos derivan, en mayor o menor grado, de la $\breve{s}^{c} a$, grupo de partidarios de ${ }^{\mathrm{c}} \mathrm{Alî}$, el yerno del Profeta desposeído del califato por los ortodoxos en el s. VII. Su principal base pasó a Iraq, donde fueron organizándose para combatir a los sunníes y

\footnotetext{
${ }^{20}$ Hopwood, 1988, 9; Alem, 1968, 21, 23; Palazzoli, 1977, 56; Rondot, 1978, 71; Longrigg, 1958, 9.
} 
convirtiéndose en una nueva doctrina. Al negar la legitimidad de Abû Bakr, rechazaban la de los sucesivos califas. Mantenían que cAlî había recibido la investidura divina, oponiendo a los califas elegidos sus imâmes designados por Dios, y a la concepción ortodoxa del consenso general $\left(i \hat{y} m \hat{a}^{c}\right)$, la de la obediencia a jefes religiosos infalibles. Sus sentimientos se intensificaron con la muerte de los hijos de ${ }^{c}$ Alî, H Husayn y Ḥasan, cuyo martirologio celebran anualmente. Su religión es muy intensa: esperan el retorno de los imâmes, encargados de concluir la misión de Muhammad, y su mayor premio es el martirio luchando por la causa. El šŝcismo se ha extendido por todo el mundo. Es mayoritario en Irán y cuenta con importantes comunidades en Iraq, Yemen y Líbano.

Considerados herejes por los sunníes, han sido muy perseguidos y han solido buscar refugio en zonas montañosas. En la región siro-libanesa los principales conflictos religiosos no se dieron entre musulmanes y cristianos, sino entre los propios musulmanes. Desde los primeros tiempos del Islam la hostilidad entre los ortodoxos y los disidentes era muy violenta. Los šîcíes fueron diezmados por la represión de omeyas, cabbâsíes, ayyûbíes y mamelucos. Los otomanos, sunníes, les tratarían peor que a los cristianos, no reconociendo su status de sectas separadas. Para resistir la presión del entorno debieron adherirse al disimulo (taqîya) de sus convicciones frente a sus adversarios, lo que hace que su número sea difícil de contabilizar. Aunque hoy día esa hostilidad ha desaparecido en líneas generales, la taqîya ha sobrevivido. El šŝcismo primitivo se ha dividido en multitud de ramas esotéricas, entre las que destacan los metwalíes, los ismâcîlíes, los calawíes y los drusos.

- Ṣ̆̂cíes metwalíes ${ }^{21}$.

Los ṣ̂$^{c}$ íes libaneses, llamados metwalíes (mutawâlin, pl. matâwila), son el grupo más destacado de la $\breve{s} \imath^{c} a$ (s. VII). Probablemente de raza aramea, proceden del interior de Siria, donde hoy son muy minoritarios. Nómadas, se extendieron por el valle de la Bekaa, y una de sus tribus más turbulentas, los Hạââda, ganan los montes de ${ }^{\mathrm{c} A k k a ̂ r, ~ l a ~ r e g i o ́ n ~ d e ~ T i r o ~ y ~}$ los montes de Palestina, posiblemente en el s. IX. Luego se diseminan por Kesruan y el llano de Beirut. Actualmente ocupan casi las mismas zonas: Montes Hermel y la Bekaa (24\%) ${ }^{\mathrm{c} A k k a ̂ r}(1 \%)$, Monte Líbano (9\%), Beirut (7\%), la región de Tiro -donde reside su Muftî- y el Líbano sur (59\%). En esta última zona son mayoritarios, y por tanto los más expuestos a la invasión israelí y los principales protagonistas de la tragedia. En general sus comunidades están casi fuera del Monte Líbano, situadas a lo largo de las fronteras con otros países y en la costa.

La zona sur y la Bekaa, subdesarrolladas respecto al conjunto libanés, son terreno fértil para ideologías revolucionarias. Además los š̂̃cíes son muy prolíficos y se han extendido mucho, hasta llegar a componer el humus de los suburbios que circundan Beirut. Son los que ofrecen mayor número de postulantes en el mercado de trabajo. Hoy día parece que se han convertido en la población mayoritaria del país.

\footnotetext{
21 Alem, 1968, 21, 109; de Bar, 1983, 19-20, 22-24; F.M.A., I-L17; Benassar, 1978. 213-214; Longrigg, $1958,8$.
} 
Su composición social es contrastante: unas pocas familias dirigentes de señores feudales someten a una gran masa rural, laboriosa, pobre y atrasada, con fuerte sentido de clan. Montañeses en su mayoría, soportaron -con maronitas y drusos- el exclusivismo religioso sunní de los otomanos. Por su condición de eternos perseguidos tienen gran capacidad de adaptación y evolución, espíritu abierto y afán de mejora.

Como en el Mandato eran la $3^{\text {a }}$ comunidad del Líbano, desde 1943 detentan la Presidencia de la Cámara de Diputados. Los metwalíes nacen y mueren árabes, pero viven sintiéndose libaneses. Entre sus filas prosperan las ideas progresistas y marxistas. Cuentan con el Partido del Pueblo y las milicias de Amal. Al contrario que los sunníes, la juventud šîcí es libanesista, pues sabe que sólo pueden tener futuro en el Líbano, por el predominio sunní que habría en la unión con otros países árabes; y reprochan a los sunníes que sigan las órdenes de Damasco o El Cairo.

\section{- Drusos 22 .}

El origen de los drusos (durzî, pl. durûz) también es discutido. El emir Fajr al-Dîn había extendido por Europa la leyenda de que los drusos eran descendientes de los cruzados que escaparon a la matanza de S. Juan de Acre en 1291 y que su nombre derivaba del conde Dreux. Pero, según Alem (1968, 22-23), son una secta herética procedente del ismâcîlismo. El extravagante califa fâtimí al-Ḥakîm bi-Amr Allâh (985-1020/21) declaró que la divinidad se había encarnado en él. Su nueva religión no encontró casi adeptos entre los egipcios, y Hakîm fue asesinado. Pero antes de su muerte había enviado a Siria a dos de sus discípulos, Hamza bn. 'Alî e Ismâcîl al-Darrazî, del que procede el nombre de drusos. Los enviados se detuvieron al pie del monte Hermon, en Wâdî Taym, -región de Hậșbayâ y Râsayyâ- llena de grupos š̂̃̂́ís. Chocaron con la hostilidad de los nușayríes, pero tuvieron éxito entre los ismâcîlíes. Tras asesinar a Darrazî, Hamza llevó su predicación hasta Alepo, donde renunció al proselitismo y cerró la secta, ya que las presiones musulmanas y las querellas internas amenazaban con dividirla. A partir del s. X, los drusos de Alepo y Wâdî Taym se reagruparon en el Chuf, Metn y Garb, su hábitat actual en el Líbano, y durante siglos compartieron la montaña libanesa con los maronitas. Para evitar la represión tras la matanza de cristianos de 1860, parte de ellos marchó al Hạwân, al sur de Siria, donde se les unieron otros grupos venidos de Alepo. Desde entonces estas montañas se llamarían Monte Druso (Ŷabal al-Durûz), donde está la otra mitad de la población drusa. Su santuario está cerca de Hạsbayâ, en Jalawât al-Bayâḍa.

El hermetismo único de esta secta, su aislamiento, su esoterismo, su carácter iniciático y su adhesión a la taqîya van a reflejarse también en el secreto de su dogma, que sólo conocen los iniciados (ajawies). Los drusos se llaman a sí mismos "unitarios" (muwahhidûn), y su doctrina se centra en la creencia en el retorno del imâm Hạâim y en la reencarnación. Como en ella se sincretizan elementos islámicos, cristianos, hindúes o

22 Alem, 1968, 22-23, 40, 44-45; Palazzoli, 1977, 56; Rondot, 1978, 72-73; Longrigg, 1958, 8-9; Tibawi, 1969, 99-100; Palazzoli, 1977, 56; Hopwood, 1988, 10; de Bar, 1983, 127, 131-137, 211; F.M.A., I-L17; Koury, 1976, 5 . 
zoroástricos, son tratados como herejes en el Islam, pero los drusos niegan serlo, ya que sus costumbres, su apariencia y su discurso son similares a los islámicos, y su raza, árabe. Su identificación con la mayoría musulmana se demostró en su revuelta de 1925-26 contra los franceses, así como en su posterior intervención en los debates sobre nacionalismo.

Aunque relativamente escasos (130.332 en 1976), han jugado un papel capital en la historia del Líbano, especialmente desde el siglo XVI al XIX -con los emires $\mathrm{Ma}^{\mathrm{c}}$ an y Šihâb- en coexistencia con los maronitas, y a veces en oposición a ellos. Su emîr Fajr alDîn es considerado por muchos como el fundador del Líbano, pues logra vivir con una cierta independencia de los turcos y extender sus dominios incluso fuera de las fronteras del Líbano actual.

Orgullosos y leales, tienen un fuerte sentido del honor; disciplinados y con gran espíritu belicoso y gregario, sienten aversión hacia los extraños, huyen de los matrimonios mixtos y tratan de prohibir la apostasía y la conversión. Ferozmente independientes, se han rebelado cada vez que su autonomía estaba en peligro. Gracias a este carácter, dominaron la montaña y han conservado sus particularismos. Eligen a sus jefes, los emires, y no reconocen ninguna otra autoridad. Están sometidos a su propia aristocracia y a sus familias gobernantes.

En su composición social destacan unas pocas familias feudales, dueñas de grandes fortunas, algunos pequeños terratenientes, y una gran masa campesina inculta. Por su origen montañés, son una comunidad eminentemente rural, a excepción de unos pocos ciudadanos de reciente implantación y algunos hombres de negocios. Aún así, el 5\% de la riqueza nacional está en sus manos.

Muy aferrados a su tradición feudal, han conservado su división en clanes, algunos originados ya en tiempos de Fajr al-Dîn: los Yasbakî, drusos del Garb y Beirut, que reconocen la autoridad del emir Arslân, y los Ŷumblați, drusos del Chuf, con jefes como Kamâl o Walîd Ŷumblât (Ŷmbulât). Las rivalidades entre estos clanes han sido frecuentes, pero a partir de 1962 se pusieron de acuerdo para alternarse en la dirección de su Consejo.

En 1932 ocupaban el $5^{\circ}$ puesto entre las comunidades libanesas, por lo que les está encomendado uno de los Ministerios clave, el de Defensa. El peso de sus ministros es importante, y sus representantes en la Cámara son emanación de su oligarquía feudal. Su política es muy contradictoria. Esta contradicción aparente, pero coherente en sentido druso, la encarna la figura de su jefe Walîd Ŷumblât, pues el señor feudal de Mujtâra es el líder de la izquierda proletaria y progresista. Por otro lado, hay que destacar la tradicional complementariedad druso-maronita, o solidaridad de la montaña, que les favorece. Gracias a ella y a su libanesismo, ocupan un buen lugar en el ejército. Pero los drusos son una comunidad que está disminuyendo, ya que muchos de sus miembros se han ido convirtiendo al cristianismo maronita.

- ${ }^{\mathrm{c} A l a w i ́ e s}{ }^{23}$.

${ }^{23}$ Hopwood, 1988, 9-10; Palazzoli, 1977, 54-55; Rondot, 1978, 71-72.. 
Llamados también nușayríes o anșâríes, profesan una extraña doctrina, mezcla de elementos islámicos, cristianos, paganos y gnósticos. Derivados del ṣ̌̂ismo, su sincretismo les coloca en el margen extremo del Islam: dicen ser musulmanes, pero algunos sunníes estrictos no les reconocen como tales. Rezan en dirección al sol, no a la Meca, pues creen que ${ }^{\mathrm{c}}$ Alî -hacia el que sienten especial veneración- habita allí. Son adeptos a la taqîya y creen en la transmigración. En el pasado han luchado ferozmente contra ismâcîlíes, drusos y sunníes y han sido objeto de duras persecuciones a lo largo de su historia. Importante minoría en Siria, donde su presidente actual pertenece a esta secta, hicieron apariciones por el norte del Líbano ( ${ }^{\mathrm{c} A k k a ̂ r) ~ o ~ e n ~ c i u d a d e s ~ c o s t e r a s, ~ c o m o ~ T r i ́ p o l i, ~ p e r o ~ h o y ~ c a s i ~ h a n ~}$ desaparecido al replegarse a la montaña calawí en Siria. Hablan el árabe -a veces el kurdo- y forman una población rural, pobre y poco instruida, obediente a sus señores feudales, cuyas tierras cultivan, junto a las de los sunníes, o viven en las ciudades costeras mezclados con elementos cristianos. Por su número, su papel en la vida del país es de escasa importancia.

- Ismâcîlíes ${ }^{24}$.

Este grupo disidente del Islam y fiel al Aga Khan, apenas está representado en el Líbano actual, pero históricamente tiene su importancia por haber dado origen a la disidencia drusa.

\section{PROBLEMATICA COMUNITARIA.}

Francia, tradicional protectora de los cristianos de Oriente Medio, no encuentra otra forma de protegerlos al recibir la región siro-libanesa en régimen de Mandato (1918-20) que crear el Gran Líbano como estado separado, dejando a los cristianos en mayoría frente a los musulmanes. Además optó por un régimen confesional, sistema político único en que el - poder se repartiría entre las comunidades según sus proporciones numéricas, estableciéndose después una ratio fija de 6 cristianos por cada 5 musulmanes. Pero la mayoría cristiana era muy ajustada, como se refleja en el Censo de 1932: 49,54\% de cristianos frente a 48,41\% de musulmanes ${ }^{25}$.

La necesidad de conciliar los intereses de las diversas comunidades, todas ellas minoritarias, ha llevado al mantenimiento de este sistema confesional, sin variar la ratio establecida, aunque con el paso del tiempo las proporciones han variado sustancialmente. Desde 1932 no se ha elaborado un censo de la población, a pesar de las muchas veces que se ha intentado. La razón es básicamente política, pues demostraría que las cifras en que se sigue basando el actual reparto del poder no se corresponden con la realidad.

Hay muchas dificultades para elaborar un nuevo censo: no se han puesto al día los registros de época otomana; en 1958 se quemaron muchos registros; los nacimientos, matrimonios y muertes son registrados por los jefes de las comunidades; las gentes que se desplazan a la ciudad siguen inscritas en sus aldeas de origen; las reintegraciones y naturalizaciones no siempre se recogen, etc... Pero la razón fundamental es que el reparto

\footnotetext{
24 Alem, 1968, 21 .

25 Mansfield, 1983, 71-72. El censo de 1932 lo recoge López García (1985, 218-129).
} 
comunitario variaría si se incluyera al abultado número de emigrantes o de refugiados palestinos. Este problema es uno de los puntos cruciales de discusión a la hora de elaborar el censo, ya que las comunidades no se ponen de acuerdo en los criterios a seguir. Los cristianos quieren que consten todos los inscritos en el registro civil de sus comunidades, sean residentes o emigrados, ya que esto mantendría la mayoría maronita. Si se optara por aquellos que mantienen su nacionalidad libanesa, también habría problemas, ya que no existe tradición de registro consular y el Estado no puede saber quiénes están fuera sólo de forma transitoria. Por otro lado, los musulmanes sólo admiten a los residentes, con lo que quedaría de manifiesto la preponderancia musulmana, especialmente la šŝc ${ }^{c}$. A su vez, los sunníes verían incrementado su número si se contabilizara a los numerosos refugiados palestinos, que en su mayor parte pertenecen a su comunidad, por lo que no serían

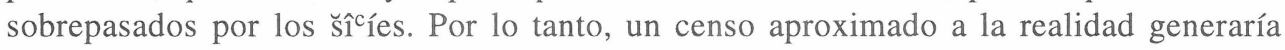
importantes dificultades políticas y las élites gobernantes prefieren mantener el statu quo de las proporciones asignadas por la Constitución de 1926 y el Pacto Nacional de 194326.

La ausencia de un censo actualizado obliga a recurrir a diferentes tipos de estadísticas, a menudo elaboradas con ocasión de unas elecciones. Son generalmente sesgadas y parciales, a veces no incluyen referencias de orden confesional, y varían considerablemente entre sí, según den cifras de población o establezcan el porcentaje de cada grupo, por lo que sólo tienen un valor orientativo.

Respecto a la población general, se pueden recoger las siguientes estimaciones ${ }^{27}$ :

- En 1865: en el Monte Líbano la población era de 266.661 habitantes.

- En 1932: en el nuevo Líbano había 798.247 habitantes.

- En 1953: 1.410.000 habitantes.

- En 1964: 2.150.000 libaneses residentes, además de 1.214.000 emigrantes, en su mayoría cristianos, en América, Egipto, Australia o Africa Occidental.

- En 1966: 2.000.000 residentes, de ellos 1.610 .000 eran libaneses, 205.000 extranjeros y 166.264 refugiados palestinos. También se estimaban 1.110 .000 emigrados, de los cuales de 300.000 a 350.000 seguían teniendo nacionalidad libanesa.

- En 1968: 2.580 .000 residentes, de ellos 360.000 extranjeros (50\% palestinos y 35\% sirios). No hay estadísticas sobre los que habían conseguido la nacionalidad libanesa, aunque el gobierno tendía a restringir su concesión. El conjunto de emigrantes variaba entre 500.000 y 1.000 .000 .

- Entre 1970 y 1977: 3.000.000 de habitantes. En Siria, hacia 1973, había de 300.000 a 400.000 refugiados libaneses, a causa de la guerra civil.

- En 1983: 3.100.000 habitantes.

- En 1990: 2.700.000 habitantes.

\footnotetext{
26 Según de Bar $(1983,193)$, los maronitas emigrados y sus desdendientes se estiman en un millón. Los refugiados palestinos en el Líbano son unos 200.000 ó 300.000 en 1964, según Gordon (1980, 41); en 1980 se estimaban en 330.000 ó 600.000, según se incluyera o no a los naturalizados (F.M.A., I-L20).

27 Las cifras las recogen Gordon $(1980,41)$, Mansfield $(1973,399)$, Alem $(1968,106)$, Willemart $(1969,162)$, Rodinson $(1979,87)$, Rondot $(1978,13)$, M.E.N.A. $(1984,507)$ y el Anuario de El País $(1993,54)$
} 
En lo referente a las cifras de cada confesión, los porcentajes fijos quedan reflejados en la distribución de escaños parlamentarios; pero en las estimaciones de las diversas fuentes ${ }^{28}$ hay pocas referencias posteriores a 1932 sobre porcentajes reales, por razones evidentes:

- En 1861: el 76\% de los habitantes del Monte Líbano eran maronitas.

- En 1932: el 49,54\% eran cristianos (28\% maronitas) y el $48,41 \%$ musulmanes $(22 \%$ sunníes y $16 \%$ ṣ̌̂íes) en el nuevo Líbano.

- En 1964: se estimaba un 52,7\% de cristianos (29\% maronitas) y un 45,3\% de musulmanes ( $20,8 \%$ sunníes y $18,2 \%$ š̂̀íes).

- En 1968: la mayoría era maronita, con un 30\% de la población, y una ligera mayoría de

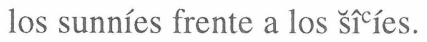

- En 1983: se estimaba ya un 60\% de musulmanes, pues eran cerca de 1.950 .000 , frente a 1.150 .000 cristianos.

De todo este embrollo de cifras se pueden sacar varias conclusiones, además de su imprecisión y falta de fiabilidad:

- La primacía maronita en el Monte Líbano desde los tiempos otomanos, que llevará a Francia a organizar el nuevo Estado del Líbano para consolidar la posición de los cristianos.

- El estancamiento de la población a partir de la guerra civil (1975).

- El incremento de la proporción de los musulmanes, tan celosamente ocultado, que les sitúa en mayoría en la actualidad.

- La importancia numérica de los refugiados palestinos o los emigrados como factor desequilibrante del statu quo.

Por otro lado, la distribución geográfica de los diferentes grupos religiosos es muy irregular. De forma general, los maronitas y los drusos predominan en el Monte Líbano; los sunníes, en Beirut y en la zona norte; los š̂̃ ${ }^{\complement} i ́ e s$, en el sur y la Bekaa, y los greco-ortodoxos son numerosos en el norte. Además, las distintas comunidades están muy mezcladas en todas las zonas ${ }^{29}$.

Las estadísticas también son parciales e imperfectas a la hora de evaluar el crecimiento demográfico. Los registros son más correctos en Beirut, las grandes ciudades y el Monte Líbano que en las aldeas del interior, donde los nacimientos se registran mejor que las muertes. El crecimiento es mucho mayor entre los musulmanes que entre los cristianos, que a su vez emigran más ${ }^{30}$. Esto ha llevado a un desequilibrio inter-comunitario, lo que produce la mayor parte de los enfrentamientos, debidos a la frustración de una minoría que se ha convertido de hecho, aunque no de derecho, en mayoría.

En el terreno económico, el gran impulso mercantil tras la segunda guerra mundial ha trastocado el poder político, asentado desde antiguo en la aristocracia terrateniente y semi-

${ }^{28}$ Las cifras las recogen Gordon (1980, 38), Alem (1968, 106), Mansfield (1973, 399), de Bar (1983, 194), y M.E.N.A. $(1984,507)$.

29 Cfr. Gordon, 1980, 42 .

30 Willemart, 1969, 161-163. 
feudal, y ha dado lugar a una mayor movilidad social y a la eclosión de las clases medias, especialmente ciudadanas, hecho que se une al incremento del éxodo rural. Por otro lado, el nivel de vida ha subido, pero de forma irregular, ya que los gobiernos han hecho poco por las clases desfavorecidas, los servicios de bienestar han estado a cargo de instituciones privadas o religiosas y las organizaciones laborales, aún débiles y fragmentadas, poco han podido hacer en pro de las reformas sociales ${ }^{31}$. Las diferencias económicas intercomunitarias son, pues, otro factor de inestabilidad.

El nivel de instrucción y cultural es de los más altos de su entorno, incluso comparado con algunos países del sur de Europa, pero también desigual. En la enseñanza primaria, los datos no son muy favorables; las enseñanzas técnicas y profesionales, tan vitales para el desarrollo económico, también están descuidadas; y existe un alto nivel de analfabetismo, variable según las regiones y las comunidades. En la enseñanza secundaria y la superior los niveles de calidad son superiores, pero, al estar en gran medida en manos de instituciones privadas, resultan prohibitivas para una gran mayoría de jóvenes de muchas comunidades. El Líbano cuenta con 4 universidades, entre las que destacan dos de origen extranjero, creadas en el s. XIX por misiones cristianas y con enseñanza en lenguas extranjeras: la de los jesuitas de St. Joseph -en francés- y la presbiteriana Universidad Americana de Beirut -en inglésambas más accesibles a los cristianos que a los musulmanes, por diferentes razones ${ }^{32}$.

Políticamente, la sociedad libanesa está en transición hacia unas formas más modernas de organización: las estructuras religiosas ancestrales están fuertemente arraigadas, y a ellas se van superponiendo poco a poco otras organizaciones de cuño más moderno. A pesar de las recientes tentativas de laicización fomentadas por esas nuevas formaciones, el espíritu comunitario de tipo confesional sigue siendo el eje de la vida del país. Su gran fragmentación en comunidades da lugar a un fuerte individualismo y cerramiento comunitario que contrasta con su unión en los momentos difíciles. El cerramiento se debe a su pasado de grupos perseguidos, donde el individuo sólo encontraba refugio entre las gentes de su comunidad; esto creaba una red de relaciones intra-comunitarias que estará en la base del clientelismo de sus formaciones políticas tradiciones ${ }^{33}$. Por otro lado, a lo largo de su historia siempre ha habido una entente entre los diversos grupos. Los inevitables conflictos inter-comunitarios, algunos de ellos muy graves, han acabado por remontarse siempre que esa "nación" -cuya unión ha sido más forzada que natural- ha estado en peligro. Como dice Pierre Gemayel, jefe de las Falanges libanesas, "si el Líbano ha resistido en 1958, nada podrá quebrantarlo en el futuro"34.

La gran variedad de comunidades (con su irregular distribución territorial y su interpenetración, sus diferentes niveles socioeconómicos y culturales y sus distintas ópticas nacionalistas) hace que el equilibrio político del Líbano actual sea más complejo y delicado

\footnotetext{
31 Willemart, 1969, 163; Mansfield, 1973, 411.

32 Willemart, 1969, 163-194; Mansfield, 1973, 411. En 1966-67 había 1.000 escuelas públicas frente a 1.200 privadas, según Mansfield $(1973,411)$.

33 Gordon, 1980, 143; Willemart, 1969, 159-160

34 Cit. por Willemart (1969, 161-162).
} 
aún que el de la montaña libanesa. La complejidad de sus instituciones, la fragmentación de sus organizaciones políticas y sus milicias, el desigual reparto del poder político, y en definitiva el inmovilismo e injusticia que se derivan de su sistema confesional, imposibilitan la estabilidad y prosperidad necesarias para la subsistencia del Líbano.

\section{BIBLIOGRAFIA}

ALEM, Jean Pierre: Le Liban. P.U.F. París, 1968.

BAR, Luc Henri de: Les communautés confessionnelles du Liban. Ed. Recherches sur les civilisations. París, 1983.

BENASSAR: Anatomie d' une guerre et d' une occupation. Evenements du Liban de 1970 a 1978. París, 1978.

(F.M.A.) Fichas del Mundo Arabe. Nicosia. (Varios años).

GORDON, David C.: Lebanon. The Fragmented Nation. Londres, 1980.

HOPWOOD, Derek: Syria, 1945-1986. Politics and Society. Unwin Hyman. Londres, 1988.

KOURY, Enver M.: The Crisis in the Lebanese System. Confessionalism and Chaos. American Enterprise Institute for Public Policy Research. Washington D.C., 1976.

- La tragedia del Sur del Líbano. Un estudio documentado. Liga Arabe. Beirut, 1981.

LONGRIGG, S.H.: Syria an Lebanon under French Mandate. Oxford University Press. Londres, 1958.

LÓPEZ GARCÍA, Bernabé y C. Fernández Suzor: Introducción a los regímenes y constituciones árabes. Centro de Estudios Constitucionales. Madrid, 1985.

MANSFIELD, Peter: The Middle East. A Political and Economic Survey. Oxford University Press. Londres, 1973.

(M.E.N.A.) The Middle East and North Africa. 1984-1985. Europa Publications Ltd. Londres, 1984.

PALAZZOLI, Claude: Syrie, le rêve et la rupture. Le Sycomore. París, 1977.

PAREJA, F.M.: Islamología. Ed. Razón y Fe. Madrid, 1954.

RODINSON, Maxime. Les arabes. P.U.F. París, 1979.

RONDOT, Philippe: La Syrie. P.U.F. París, 1976.

TIBAWI, A.L.: A Modern History of Greater Syria, Including Lebanon and Palestina. Macmillan. Londres, 1969.

WILlEMART, H. y P.: Dossier du Moyen-Orient arabe. Géographie/ Economie/Politique. Marabout University. Verviers (Bélgica), 1969. 